\title{
A Novel Approach of Development of Web Pattern by Focusing on Web Structure Mining Techniques
}

\author{
Prabhat Kumar Bharti* \\ (Asst. Prof.) \\ Dept. of Computer Science and \\ Engineering \\ Goel Institute of Technology and \\ Management \\ Lucknow, India \\ e-mail:dept.csprabhat@gmail.com
}

\author{
Deena Nath \\ (Asst. Prof.) \\ Dept. of Computer Science and \\ Engineering \\ Goel Institute of Technology and \\ Management \\ Lucknow, India \\ e-mail: sonu.deena19@gmail.com
}

\author{
Vandana Yadav \\ (Asst. Prof.) \\ Goel Institute of Technology and \\ Management \\ Lucknow, India \\ e-mail:-Vandanayadav771@gmail.com
}

\begin{abstract}
The World Wide Web is a very useful and interactive resource of information like hypertext, multimedia etc. When we search any information on the Google, there are many URL's has been opened. The bulk amount of information becomes very difficult for the users to find, extract and filter the relevant information, so that some techniques are used to solve these problems. The objective of current manuscript is focus on processing of structured and unstructured data mining. With the tremendous growth in website, web portal to provide downloaded data to the user. The semantic web is about machine-understandable web pages to make the web more intelligent and able to provide useful services to the users. The data structure definition and recognition is to estimate the accurate page ranking and to produce better result while searching operation with web data.
\end{abstract}

Keywords-Web Structure, Weighted Page Rank, Topic Sensitive Page Rank and TC-Page Rank, Hypertext Induced Topic Search. $* * * * *$

\section{INTRODUCTION}

Web structure Mining concentrates on link structure of the web site. The different web pages are linked in some fashion. The potential correlation among web pages makes the web site design efficient. This process assists in discovering and modeling the link structure of the web site. Generally, topology of the web site is used for this purpose. The linking of web pages in the Web site is challenge for Web Structure Mining.

The structure of the web page is as shown below.

$<\mathrm{html}>$

$<$ a href= "filename" $>$ link $</ \mathrm{a}>$

$</$ html $>$

The WWW is a collection of various hyperlinked pages. The analysis of these linked pages is of very high importance. In addition to the text contents of a page, the link structure of such pages should be observed while searching for a particular resource. Consider the significance of a link A B: With such a link A recommends, that surfers visiting A follow the link and visit $B$. This may reflect the fact that pages $A$ and $B$ share a common topic of interest, and that the author of A thinks contents of page B. These links are called an informative link [1]. There are a number of link structure algorithms. In this paper I have given just an introduction of three algorithms namely PageRank, Weighted PageRank and HITS.

The Page Rank method is used by the Google Web search engine to compute the importance of Web pages. The interpretation of the Page Rank method can be seen in two different view [2] and values

(a) Stochastic or random surfer method in this method the Page Rank values can be viewed as the steady-state distribution of a Markov chain, and

(b) Algebraic method where the Page Rank values taken as the eigenvector corresponding to Eigen value of the Link structure matrix. The quality of the search results has been immensely improved by analyzing link structure of webpages [3]. The search engine Google uses an iterative algorithm that determines the importance of web pages based on the importance of its parent pages.

The logs include information about the referring pages, user identification, time a user spend at a site and the sequence of pages visited. There are number of algorithms proposed based on link analysis. But none of these algorithms talks about the temporal interest shown by a user. As the page becomes older, it earns more links. The analysis of the link structure shows about the user behavior and the amount of time spent by a user on a specific web page. This temporal interest shown by a user which changes according to the time spent by a user affects the importance of a web page. In the present paper, a different interpretation of Page Rank is proposed, namely, a dynamic systems viewpoint, by showing that the PageRank method can be formally interpreted as a particular case of the Interaction Information Retrieval method for a particular time. 
Table 1. The statistical information collected from Log File

\begin{tabular}{|c|c|}
\hline $\begin{array}{c}\text { Statistical } \\
\text { Information }\end{array}$ & $\begin{array}{c}\text { Parameters which can be } \\
\text { measured }\end{array}$ \\
\hline $\begin{array}{l}\text { History of the website } \\
\text { and users }\end{array}$ & $\begin{array}{l}\text { Number of navigators to the website } \\
\text { for a given } \\
\text { Threshold } \\
\text { Number of hits to a particular page } \\
\text { Time spent on each page } \\
\text { Users visiting a particular web page } \\
\text { Average time spent on each page } \\
\text { The longest web pages traversal } \\
\text { path } \\
\text { Association between web pages } \\
\text { Redirected or Failed or Successful } \\
\text { hits } \\
\text { Number of bytes transferred } \\
\text { Various Browsers used by clients } \\
\text { Usage of GET/POST method }\end{array}$ \\
\hline $\begin{array}{l}\text { Status Codes which } \\
\text { help for } \\
\text { troubleshooting }\end{array}$ & $\begin{array}{l}400 \text { Series- Failure Eg:404-File Not } \\
\text { Found } \\
300 \text { Series-Redirect } \\
200 \text { Series-Success } \\
500 \text { Series-Server failures }\end{array}$ \\
\hline $\begin{array}{l}\text { Grade of a Web Page } \\
\text { can be measured based } \\
\text { on } \\
\text { number of hits, time } \\
\text { spent, location of web } \\
\text { page, in } \\
\text { degree and out degree. }\end{array}$ & $\begin{array}{l}\text { Medium } \\
\text { Low }\end{array}$ \\
\hline
\end{tabular}

\section{LITERATURE REVIEW}

A Hyperlink is a structural unit that connects a location in a web page to a different location, either within the same web page or on a different webpage. There are number of algorithms proposed based on ranking. Some algorithms are Hypertext Induced Topic Search (HITS), extension of HITS, PageRank, Weighted PageRank, Topic Sensitive PageRank and TC-PageRank is discussed below.

\section{A. HITS (Hyper-link Induced Topic Search)}

A HIT is a purely link-based algorithm. It is used to rank pages that are retrieved from the Web, based on their textual contents to a given query. Once these pages have been assembled, the HITS algorithm ignores textual content and focuses itself on the structure of the Web only.

\section{B. Weighted Page Rank (WPR)}

The more popular Webpages are the more linkages that other Webpages tend to have to them or are linked to by them. The proposed extended PageRank algorithm-a Weighted
PageRank Algorithm assigns larger rank values to more important (popular) pages instead of dividing the rank value of a page evenly among its outline pages. Each outline page gets a value proportional to its popularity (its number of in links and outlines).

\section{Page Rank Algorithm}

Page ranking algorithms are the heart of search engine and give result that suites best in user expectation. Need of best quality results are the main reason in innovation of different page ranking algorithms, HITS, PageRank, Weighted PageRank, Distance Rank, Dirichlet Rank Algorithm, Page content ranking are different examples of page ranking used in different scenario. Since GOOGLE search engine has great importance now days and this affect many web users now days, so page rank algorithm used by GOOGLE become very important to researches [4].

\section{Page Rank Based on VOL}

We have seen that original Page Rank algorithm, the rank score of a page $\mathrm{p}$, is equally divided among its outgoing links or we can say for a page, an inbound links brings rank value from base page, $\mathrm{p}$ (rank value of page $\mathrm{p}$ divided by number of links on that page [5]. Which more rank value is assigned to the outgoing links which is most visited by users. In this manner a page rank value is calculate based on visits of inbound links.

\section{E. Result Analysis}

This section compares the page rank of web pages using standard Weighted PageRank (WPR), Weighted PageRank using VOL (WPRVOL) and the proposed algorithm. We have calculated rank value of each page

based on WPR, WPRVOL and proposed algorithm i.e. EWPRVOL for a web graph shown in Table2.

Table 2. Comparison of DifferentAlgorithm

\begin{tabular}{|c|c|c|c|c|}
\hline Algorithm & $\begin{array}{l}\text { Page } \\
\text { Rank }\end{array}$ & $\begin{array}{l}\text { Weighted } \\
\text { Page } \\
\text { Rank }\end{array}$ & $\begin{array}{l}\text { Page } \\
\text { Rank } \\
\text { with } \\
\text { VOL }\end{array}$ & $\begin{array}{l}\text { Weighted } \\
\text { Page } \\
\text { Rank } \\
\text { with } \\
\text { VOL }\end{array}$ \\
\hline $\begin{array}{l}\text { Web } \\
\text { mining } \\
\text { technique } \\
\text { used }\end{array}$ & $\begin{array}{l}\text { Web } \\
\text { Structure } \\
\text { mining }\end{array}$ & $\begin{array}{l}\text { Web } \\
\text { Structure } \\
\text { mining }\end{array}$ & $\begin{array}{l}\text { Web } \\
\text { Structure } \\
\text { mining, } \\
\text { web } \\
\text { usage } \\
\text { mining }\end{array}$ & $\begin{array}{l}\text { Web } \\
\text { Structure } \\
\text { mining, } \\
\text { web } \\
\text { usage } \\
\text { mining }\end{array}$ \\
\hline $\begin{array}{l}\text { Input } \\
\text { parameters }\end{array}$ & backlinks & $\begin{array}{l}\text { backlinks, } \\
\text { Forward } \\
\text { links }\end{array}$ & $\begin{array}{l}\text { Backlinks } \\
\text { and VOL }\end{array}$ & $\begin{array}{l}\text { Backlinks } \\
\text { and VOL }\end{array}$ \\
\hline Importance & More & More & More & More \\
\hline Relevancy & Less & Less & More & More \\
\hline
\end{tabular}


values of page rank using WPR, $\mathbf{W P R}_{\text {vol }}$ and EWPR $_{\text {VoL }}$ have been compared [6]. The values retrieved by EWPRVOL are better than original WPR and $\mathbf{W P R}_{\text {VOL. }}$.

The objective focuses on how to increase the performance of website using various techniques.

The second objective is analysis of link structure algorithms. Various algorithms are analyzed. The algorithms are Page Rank, Hypertext Induced Topic Search (HITS), Weighted Page Rank and variations of Page Rank. Objective also include the performance analysis of various type of ranking algorithms (manually, based on assumption). ). I have given a brief analysis of all the algorithms. algorithms are analyzed by considering (assuming) graphs which have in links, out links. The data is imaginary it is not based on facts. Inlinks also known as incoming links, inbound links, backlinks, and inward links, are incoming links to a website or web page In basic link terminology, an inlink is any link received by a web node (web page, directory, website, or top level domain) from another web node. Website is collection of WebPages or Nodes. Website is a set of related web pages containing content such as text, images, video, audio, etc. A website is hosted on at least one web server, accessible via a network such as the Internet or a private local area network through an Internet address known as a Uniform Resource Locator. When you type in a web address, click on a link, or put a query in a search engine

\section{COMPARISION OF WEBPAGE RANKING AlgORITHM}

The proposed algorithm EWPR $\mathbf{E O L}_{\mathbf{V}}$ method uses number of visits of inlinks and outlinks to calculate values of page rank and gives more rank to important pages.

Table 3. Shows Comparison of Web Page Ranking Algorithm

\begin{tabular}{|c|c|c|c|c|c|c|c|}
\hline System & PageRank & $\begin{array}{l}\text { Weighted } \\
\text { Page Rank }\end{array}$ & $\begin{array}{l}\text { Page Content } \\
\text { Rank }\end{array}$ & HITS & $\begin{array}{l}\text { Link } \\
\text { Editing }\end{array}$ & $\begin{array}{l}\text { General } \\
\text { Utility } \\
\text { Mining }\end{array}$ & $\begin{array}{l}\text { Topological } \\
\text { Frequency } \\
\text { Utility } \\
\text { Mining }\end{array}$ \\
\hline $\begin{array}{l}\text { Web mining } \\
\text { Activity }\end{array}$ & $\begin{array}{l}\text { Web } \\
\text { Structure } \\
\text { Mining }\end{array}$ & $\begin{array}{l}\text { Web structure } \\
\text { Mining }\end{array}$ & $\begin{array}{l}\text { Web content } \\
\text { Mining }\end{array}$ & $\begin{array}{l}\text { Web } \\
\text { Structure } \\
\text { Mining \& } \\
\text { Web } \\
\text { Content } \\
\text { Mining }\end{array}$ & $\begin{array}{l}\text { Web } \\
\text { structure } \\
\text { Mining } \\
\& W e b \\
\text { Usage } \\
\text { Mining } \\
\end{array}$ & $\begin{array}{l}\text { Web Usage } \\
\text { Mining }\end{array}$ & $\begin{array}{l}\text { Web } \\
\text { Structure } \\
\text { Mining } \\
\text { \&Web } \\
\text { Usage } \\
\text { Mining } \\
\end{array}$ \\
\hline $\begin{array}{l}\text { Rank } \\
\text { Assigned } \\
\text { Considering } \\
\end{array}$ & $\begin{array}{l}\text { Pages on the } \\
\text { Web }\end{array}$ & $\begin{array}{l}\text { Pages on the } \\
\text { Web }\end{array}$ & $\begin{array}{l}\text { Pages on the } \\
\text { Web }\end{array}$ & $\begin{array}{l}\text { Pages on } \\
\text { the web }\end{array}$ & $\begin{array}{l}\text { Pages in } \\
\text { the } \\
\text { website }\end{array}$ & $\begin{array}{l}\text { Pages in the } \\
\text { website }\end{array}$ & $\begin{array}{l}\text { Pages in } \\
\text { the website }\end{array}$ \\
\hline Topology & Partial & Partial & $\begin{array}{l}\text { Not } \\
\text { Considered }\end{array}$ & Partial & Partial & $\begin{array}{l}\text { Not } \\
\text { considered }\end{array}$ & Complete \\
\hline Process & $\begin{array}{l}\text { The page } \\
\text { rank for } \\
\text { each page is } \\
\text { Computed } \\
\text { During } \\
\text { indexing but } \\
\text { not during } \\
\text { query time. } \\
\text { The } \\
\text { relevance of } \\
\text { a page plays } \\
\text { an important } \\
\text { role to sort }\end{array}$ & $\begin{array}{l}\text { The } \\
\text { distribution of } \\
\text { score is } \\
\text { Unequal } \\
\text { among its out } \\
\text { links. } \\
\text { The } \\
\text { Computation } \\
\text { of scores is } \\
\text { done at } \\
\text { indexing time. }\end{array}$ & $\begin{array}{l}\text { New grades } \\
\text { are computed } \\
\text { on the fly for } \\
\text { top n pages. } \\
\text { Whenever } \\
\text { query is } \\
\text { Posted } \\
\text { relevant web } \\
\text { pages will be } \\
\text { displayed. }\end{array}$ & $\begin{array}{l}\text { Figures out } \\
\text { hub and } \\
\text { Authority } \\
\text { grades of } \\
\text { top n } \\
\text { Highly } \\
\text { Appropriate } \\
\text { pages on } \\
\text { the fly. } \\
\text { Applicable } \\
\text { as well as } \\
\text { key pages } \\
\text { are returned }\end{array}$ & $\begin{array}{l}\text { The grade } \\
\text { for each } \\
\text { page is } \\
\text { Computed } \\
\text { offline. } \\
\text { The } \\
\text { pages } \\
\text { with high } \\
\text { in degree } \\
\text { and more } \\
\text { time } \\
\text { spent are } \\
\text { Important }\end{array}$ & $\begin{array}{l}\text { The grade of } \\
\text { each page is } \\
\text { computed } \\
\text { considering } \\
\text { frequency of } \\
\text { each page \& } \\
\text { the utility of } \\
\text { each page. }\end{array}$ & $\begin{array}{l}\text { The grade } \\
\text { of each } \\
\text { page is } \\
\text { Computed } \\
\text { Using } \\
\text { Frequency, } \\
\text { Utility } \\
\text { along with } \\
\text { Topology } \\
\text { Parameters. }\end{array}$ \\
\hline
\end{tabular}




\section{CONClusion AND Future SCOPE}

It was concluded that using clustering an algorithm can be designed which is based on partitioning model. The algorithm shows that each partitioned cluster contains average of $80 \%$ of all referred pages refer by the pages within that cluster even the percentage remains approximately unchanged from the variations of cluster numbers. The processing time increases linearly as the no of processing node increases.

As the proposed technique is good for clustering, but the time consumed in clustering increases with increase in number of clusters. The reason behind is property of $\mathrm{k}$ means clustering which is sensitive to initial condition.

It causes the non-uniform cluster information for which clustering is repeated. Hence this problem can be overcome by the use of k-means ++ clustering.

\section{REFERENCES}

[1] Olston, C. and Chi, E. H. (2003) ScentTrails: Integrating Browsing and Searching

[2] on the Web. ACM Transactions on Computer-Human Interaction (TOCHI), Vol. 10, No. 3, pp. 177-197.

[3] Perkowitz, M. and Etzioni, O. (1998) Adaptive Web sites: automatically synthesizing Web pages. In Proc. of AAAI'98, pp. 727-732, July 26-30,

[4] Madison, Wisconsin, USA, ISBN 0-262-51098-7, AAAI Press.

[5] Netcraft. Web server survey, 2004.

[6] Raymond Kosala, Hendrik Blockeel, Web Mining Research: A Survey, SIGKDD Explorations, ACM SIGKD July 2000.

[7] O.etzioni. The world wield web: Quagmire or Gold Mining. Communicate of the ACM, (39)11:65-68, 1996.

[8] Rekha Jain, Dr. G. N. Purohit, Page Ranking Algorithms for Web Mining, International Journal of Computer Applications (0975 - 8887) Volume 13- No.5, January 2011.

[9] Masashi Toyoda, Masaru Kitsuregawa What's Really New on the Web? Identifying New Pages from a Series of Unstable Web Snapshots, WWW 2006, May 23-26, 2006, Edinburgh, Scotland. ACM 1-59593-323-9/06/0005.

[10] Hong T, Chiang M, Wang S H, "Mining weighted browsing patterns with linguistic minimum supports", 2002 IEEE International Conference on Systems, Man and Cybernetics, 2002, Yasmine Hammamet, Tunisia, pp. 635-639.

[11] Wen-Chen Hu, Xuli Zong, Chung-wei Lee and Jyh-haw Yeh, World Wide Web Usage Mining Systems and Technologies.

[12] Hiroyuki Kawano, Yoshida Hommachi Sakyo-ku, Applications of web mining - from web search engine to P2P filtering.

[13] Nielsen, J. (2000) Designing Web Usability. New Riders Publishing, Indianapolis,Indiana, USA.

[14] Farkas, D. K. and Farkas, J. B. (2000) Guidelines for Designing Web Navigation. Technical Communication, 47(3), pp. 341-358, August.

[15] Lennart Björneborn and Peter Ingwersen (2004). "Toward a Basic Framework for Webometrics". Journal of the American
Society for Information Science and Technology 55 (14): 1216-1227

[16] Ryan McFadden" Web Usage Patterns" IST 497E December 5,2002

[17] Ko Fujimura, Takafumi Inoue and Masayuki Sugisaki,, "The EigenRumor Algorithm for Ranking Blogs", In WWW 2005 2nd Annual Workshop on the Weblogging Ecosystem, 2005.

[18] SANJAY MADRIA, SOURAV S BHOWMICK, W. -K NG, E. P. LIM(1999) "Research Issues in Web Data Mining" Centerfor Advanced Information Systems, School of Applied Science Nanyang Technological University

[19] Jaideep Srivastava, Prasanna Desikan , Vipin Kumar (2003)“ Web Mining - ccomplishments \& Future Directions" computer science department pp.51-61

[20] P. Desikan, J. Srivastava, V. Kumar, P.-N. Tan, "Hyperlink Analysis - Techniques \& Applications", Army High Performance Computing Center Technical Report, 2002.

[21] K. Wang and H. Lui, "Discovering Typical Structures of Documents: A Road Map Approach", in Proceedings of the ACM SIGIR Symposium on Information Retrieval, 1998.

[22] Chuang-Hue Moh, Ee-Peng Lim, Wee Keong Ng, "DTDMiner: A Tool for Mining DTD from XML Documents", WECWIS 2000: 144-151.

[23] Ji-Rong Wen, "Enhancing Web Search through Web Structure Mining" 2009, IGI Global

[24] Andrei Broder, Ravi Kumar et. al "Graph structure in the web" http://www9.org/w9cdrom/160/160.html, 2003

[25] Kumar et. al. (1) 99. R. Kumar, P. Raghavan, S. Rajagopalan, and A. Tomkins. Trawling the Web for cyber communities, Proc. 8th WWW , Apr 1999.G. Eason, B. Noble, and I. N. Sneddon, "On certain integrals of Lipschitz-Hankel type involving products of Bessel functions," Phil. Trans. Roy. Soc. London, vol. A247, pp. 529-551, April 1955.

[26] J. Clerk Maxwell, A Treatise on Electricity and Magnetism, 3rd ed., vol. 2. Oxford: Clarendon, 1892, pp.68-73.

[27] I. S. Jacobs and C. P. Bean, "Fine particles, thin films and exchange anisotropy," in Magnetism, vol. III, G. T. Rado and H. Suhl, Eds. New York: Academic, 1963, pp. 271-350.

[28] R. Nicole, "Title of paper with only first word capitalized," J. Name Stand. Abbrev., in press.

[29] Y. Yorozu, M. Hirano, K. Oka, and Y. Tagawa, "Electron spectroscopy studies on magneto-optical media and plastic substrate interface,” IEEE Transl. J. Magn. Japan, vol. 2, pp. 740-741, August 1987 [Digests 9th Annual Conf. Magnetics Japan, p. 301, 1982].

[30] M. Young, The Technical Writer's Handbook. Mill Valley, CA: University Science, 1989.

[31] D. Kornack and P. Rakic, "Cell Proliferation without Neurogenesis in Adult Primate Neocortex," Science, vol. 294, Dec. 2001, pp. 2127-2130, doi:10.1126/science.1065467.

[32] H. Goto, Y. Hasegawa, and M. Tanaka, "Efficient Scheduling Focusing on the Duality of MPL Representatives," Proc. IEEE Symp. Computational Intelligence in Scheduling (SCIS 07), IEEE Press, Dec. 2007, pp. 57-64, doi:10.1109/SCIS.2007.357670 